\title{
Sleep Deprivation Differentially Impairs Cognitive Performance in Abstinent Methylenedioxymethamphetamine ("Ecstasy") Users
}

\author{
Una D. McCann, ${ }^{1}$ Michael J. Wilson, ${ }^{2}$ Francis P. Sgambati, ${ }^{1}$ and George A. Ricaurte ${ }^{2}$ \\ Departments of ${ }^{1}$ Psychiatry and ${ }^{2}$ Neurology, The Johns Hopkins School of Medicine, Baltimore, Maryland 21224
}

\begin{abstract}
Methylenedioxymethamphetamine (MDMA; "Ecstasy") is a popular recreational drug and brain serotonin (5-HT) neurotoxin. Neuroimaging data indicate that some human MDMA users develop persistent deficits in brain 5-HT neuronal markers. Although the consequences of MDMA-induced 5-HT neurotoxicity are not fully understood, abstinent MDMA users have been found to have subtle cognitive deficits and altered sleep architecture. The present study sought to test the hypothesis that sleep disturbance plays a role in cognitive deficits in MDMA users. Nineteen abstinent MDMA users and 21 control subjects participated in a 5 dinpatient study in a clinical research unit. Baseline sleep quality was measured using the Pittsburgh Sleep Quality Inventory. Cognitive performance was tested three times daily using a computerized cognitive battery. On the third day of admission, subjects began a $40 \mathrm{~h}$ sleep deprivation period and continued cognitive testing using the same daily schedule. At baseline, MDMA users performed less accurately than controls on a task of working memory and more impulsively on four of the seven computerized tests. During sleep deprivation, MDMA users, but not controls, became increasingly impulsive, performing more rapidly at the expense of accuracy on tasks of working and short-term memory. Tests of mediation implicated baseline sleep disturbance in the cognitive decline seen during sleep deprivation. These findings are the first to demonstrate that memory problems in MDMA users may be related, at least in part, to sleep disturbance and suggest that cognitive deficits in MDMA users may become more prominent in situations associated with sleep deprivation.
\end{abstract}

\section{Introduction}

Methylenedioxymethamphetamine (MDMA; "Ecstasy") is a popular drug of abuse that once again is increasing in popularity among adolescents and young adults in the United States (Johnston et al., 2009). Research in animals has shown that MDMA can lead to lasting dose-related and protracted reductions in a variety of brain serotonin (5-HT) axonal markers (Schmidt, 1987; Ricaurte et al., 1992; Hatzidimitriou et al., 1999; Mechan et al., 2006; for review, see Green et al., 2003). Although MDMA-related neurotoxicity is dose related, even single doses of MDMA in the range of those used by humans are associated with significant lasting reductions in 5-HT axonal markers in animals (Schmidt, 1987; Colado et al., 1997), including nonhuman primates (Ricaurte et al., 1988). Neuroanatomical studies with immunochemical markers indicate that losses of axonal markers are secondary to a distal axotomy of 5-HT neurons, with sparing of the 5-HT cell body (O'Hearn et al., 1988; Hatzidimitriou et al., 1999).

Humans also appear to be susceptible to MDMA neurotoxicity. In particular, positron emission tomographic (PET) and

Received Sept. 18, 2009; revised 0ct. 1, 2009; accepted 0ct. 5, 2009.

This work was supported by United States Public Health Service Grants DA16563 (U.D.M.) and DA05938 and DA01796401 (G.A.R.) and by National Center for Research Resources Grant M01RR002719 (D. Ford). We thank Emily Dotter and Kristen Kelley for research assistance and the Clinical Research Unit/Institute for Clinical Translational Research nursing staff for their participation in the execution of these studies.

Correspondence should be addressed to Dr. Una D. McCann, Department of Psychiatry, The Johns Hopkins School of Medicine, 5501 Hopkins Bayview Circle, Room 5B71c, Baltimore, MD 21224. E-mail: umccann@jhmi.edu. DOI:10.1523/JNEUROSCI.4654-09.2009

Copyright $\odot 2009$ Society for Neuroscience $\quad 0270-6474 / 09 / 2914050-07 \$ 15.00 / 0$ single-photon emission computed tomographic imaging studies using radioligands that bind to the 5-HT transporter (SERT) provide evidence that MDMA produces lasting decrements in this structural element of the 5-HT axon terminal (McCann et al., 1998, 2005, 2008; Semple et al., 1999; Reneman et al., 2001; Buchert et al., 2003, 2004; Thomasius et al., 2006). Similar findings are seen in MDMA-treated baboons with documented 5-HT neurotoxicity (Scheffel et al., 1998), and a recent postmortem study has confirmed loss of the SERT protein in a human MDMA user who also had low levels of another 5-HT axonal marker, the tryptophan hydroxylase protein (Kish et al., 2008).

Although functional consequences of MDMA-induced brain 5-HT neurotoxicity have not been clearly defined, a large body of data indicates that abstinent MDMA users have cognitive deficits (Parrott, 2000; Kalechstein et al., 2007; de Win et al., 2008; Zakzanis et al., 2007). Working memory and verbal memory are the cognitive domains that have most consistently been found to be impaired in MDMA users, with some data indicating that poor performance on some cognitive tasks may be related to impulsive responding (Morgan et al., 2006; McCann et al., 2007; Quednow et al., 2007). Although cognitive deficits in MDMA users have not been definitively linked to MDMA-induced 5-HT injury, reductions in SERT binding, as measured by PET, have recently been found to be related to poorer working memory performance (McCann et al., 2008), and reductions in CSF 5-hydroxyindole acetic acid, another validated marker of MDMA-induced 5-HT injury (Ricaurte et al., 1988), have previously been found to be related to poorer verbal and visual memory performance (Bolla et al., 1998). 
MDMA users have also been shown to have alterations in sleep architecture (McCann and Ricaurte, 2007). Acute and chronic sleep deprivation can lead to cognitive impairment (Newhouse et al., 1989; Banks and Dinges, 2007) and, in some populations, increased impulsivity (Carskadon et al., 2004; O'Brien and Mindell, 2005). Thus, it is possible that cognitive impairments in MDMA users may, in part, be related to sleep disturbance.

The purpose of the present research was to test the hypothesis that MDMA users, by virtue of preexistent sleep loss, would be more vulnerable to the negative cognitive effects of sleep deprivation than age- and gender-matched healthy controls.

\section{Materials and Methods}

Subjects. Forty medically healthy adults ( $n=19$ MDMA users; $n=21$ controls) participated in this research. Subjects were individuals who responded to recruitment materials posted in newspapers and fliers (looking for "club drug users"), individuals who contacted our laboratory expressing interest in any ongoing research projects, individuals who responded to advertisements for healthy volunteers, or individuals who were referred by other participants. Recruitment materials did not indicate that the research was specifically directed at the effects of MDMA. To be included in the MDMA subject group, subjects needed to report that they had used MDMA on at least 25 separate occasions. Inclusion in the control group required that subjects had never used MDMA. All subjects needed to express willingness to abstain from illicit substance use for 2 weeks before study participation. Other inclusion criteria included normal results on medical screens and physical examinations and negative drug screens (with the exception of marijuana, which can remain positive for at least 3 weeks). Exclusion criteria included presence of an Axis I psychiatric diagnosis in which 5-HT has been implicated (major depression, bipolar affective disorder, obsessive compulsive disorder, panic disorder, psychosis), regular use of prescribed psychotropic medications, more than five lifetime exposures to any amphetamine other than MDMA, or drug or alcohol dependence.

Before enrollment in this research, potential subjects were first screened using an institutional review board-approved scripted phone screen. If subjects met inclusion criteria by phone screen, they were invited for face-to-face screening, at which time they provided informed consent. Before being invited for the face-to-face screening, subjects were instructed to abstain from all illicit drug use for 2 weeks and from any alcohol consumption for at least $3 \mathrm{~d}$. They were informed that they would be screened for illicit drug use at the time of the screening and that they would not be allowed to participate if drug screens were positive. Faceto-face screening measures included routine blood chemistries, human immunodeficiency virus screening, complete blood counts, and urine testing for drugs of abuse, including cannabinoids, opiates, cocaine metabolites, alcohol, and amphetamines. Subjects who continued to meet all inclusionary criteria were immediately enrolled and admitted to a controlled inpatient clinical research unit for a $5 \mathrm{~d}$ period.

During the inpatient admission, subjects were also interviewed using the Scheduled Diagnostic Interview for Diagnostic and Statistical Manual of Mental Disorders, fourth revision (SCID-I) (First et al., 1997). MDMA (and other drug) use was assessed during the initial phone screen, and by standardized drug questionnaire, nursing assessment on admission to the inpatient Clinical Research Unit, the SCID-I, and an MDMA-specific questionnaire. If subjects provided inconsistent information, they were excluded from study participation.

Sleep deprivation and cognitive measures. Cognitive performance was tested by computer three times daily for the first $4 \mathrm{~d}$ of admission, and once on the final day of admission, using the Walter Reed Army Institute of Research Performance Assessment Battery (WRAIR PAB), a computerized cognitive test battery that has previously been shown to be sensitive to the effects of sleep deprivation (Thorne et al., 1985). We have previously found abstinent MDMA users to differ from controls on several WRAIR PAB tasks when tested over a $5 \mathrm{~d}$ period (McCann et al., 1999).

The same version of the PAB that has been used previously in MDMA users (McCann et al., 1999, 2007) was used. As before, tasks included
Table 1. Subject demographics and drug use histories

\begin{tabular}{lcl}
\hline & MDMA $(n=19)$ & Control $(n=21)$ \\
\hline Gender & 12 males, 7 females & 11 males, 10 females \\
Age & $25.6 \pm 4.6$ & $23.8 \pm 3.56$ \\
Years of education & $13.5 \pm 1.5$ & $13.6 \pm 1.8$ \\
NAART score & $104.77 \pm 6.87$ & $100.90 \pm 10.14$ \\
Number of MDMA uses & $247 \pm 291.17(30-1000)$ & $\mathrm{N} / \mathrm{A}$ \\
Duration of MDMA use (months) & $58.68 \pm 49.63(12-156)$ & $\mathrm{N} / \mathrm{A}$ \\
Time since last MDMA use (months) & $5.51 \pm 1.47(0.5-36)$ & $\mathrm{N} / \mathrm{A}$ \\
Usual total dose (pills) & $2.58 \pm 1.47(1-6)$ & $\mathrm{N} / \mathrm{A}$ \\
Maximum total dose/24h (pills) & $5.50 \pm 2.5(2-10)$ & $\mathrm{N} / \mathrm{A}$ \\
Frequency of use (occasions/month) & $5.81 \pm 7.55(0.5-29)$ & $\mathrm{N} / \mathrm{A}$ \\
Marijuana use (number; frequency) & $18 ; 8.08$ & $17 ; 4.60$ \\
Hallucinogen use (number; frequency) & $14^{* *} ; 0.02$ & $4 ; 0.02$ \\
Cocaine use (number; frequency) & $10^{* *} ; 1.10$ & $1 ; 0$ \\
Opioid use (number; frequency) & $4^{*} ; 0.01$ & 0 \\
BDZ use (number; frequency) & $3 ; 0.01$ & 0 \\
Alcohol use (number; frequency) & $19 ; 7.85$ & $20 ; 3.78$ \\
Tobacco use (number; frequency) & $12 ; 15.47^{*}$ & $13 ; 4.60$ \\
\hline
\end{tabular}

Ranges are in parentheses. ${ }^{*} p<0.05$, significant difference between groups; ${ }^{* *} p<0.001$, significant difference between groups; Fisher's exact test. "Number" indicates the number of individuals in that group who have ever been exposed to the drug. "Frequency" indicates the mean number of uses per month during the previous 6 months. BZD, Benzodiazepines; N/A, not applicable.

were as follows: the Serial Add and Subtract Test, a machine-paced mental arithmetic task requiring sustained attention; the Logical Reasoning task, a self-paced task of semantic recognition and transformational grammar; the Manikin task, a visuospatial rotation task that tests the ability to mentally manipulate objects and determine the orientation of a specific stimulus; a Code Substitution task, a subject-paced complex attention and incidental learning task similar to the Digit Symbol-Coding test on the Wechsler Intelligence Scale (Wechsler, 1981); a Matching to Sample task, a machine-paced visual discrimination and working memory task; and a Delayed Recall Test, a test of recent memory.

The first three PABs on day 1 were interactive training sessions that were used to ensure that subjects adequately understood each of the seven tasks and were not used in statistical analyses. The second three PABs were used as "baseline" measures. After awakening on day 3 of the study, subjects began a $40 \mathrm{~h}$ sleep deprivation period, during which time cognitive testing continued using the same daily schedule. During the $40 \mathrm{~h}$ sleep deprivation, subjects were closely monitored by the Clinical Research Unit nursing staff to ensure no sleeping. To facilitate wakefulness during the early hours of the second morning (between 1:00 and 4:00 A.M.), when subjects generally reported the greatest difficulty in staying awake, subjects were monitored 1:1, and staff encouraged activities such as interactive card games and walks.

The Pittsburgh Sleep Quality Index (PSQI) (Buysse et al., 1989) was used to assess sleep quality and disturbances during the month before enrollment. The seven components for the PSQI include subjective sleep quality, sleep latency, sleep duration, habitual sleep efficiency, sleep disturbances, use of sleeping medication, and daytime dysfunction. Each component is self-rated from 0 to 3 . The sum for these seven components yields a global score. A global PSQI score $>5$ is indicative of clinically poor sleep.

Statistics. Statistical analyses were performed using the SAS System (version 9.1.3; SAS Institute). Accuracy and impulsivity factor (defined below) measures on the WRAIR PAB were compared using a generalized linear mixed model (Proc Mixed), adjusting for gender. First-order autocorrelation among residuals was assessed by the Durbin Watson coefficient. A first-order autoregressive covariance matrix $[\mathrm{AR}(1)]$ was used to account for time-dependent data. MDMA status was the betweengroup variable, and Time and Day were within-subject variables. For each subject, an "impulsivity factor" for each task over time was determined using a modification of a method originally established by Salkind and Wright (1977) for use in a Matching to Familiar Figures task. As before (McCann et al., 2007), the impulsivity factor was defined as 1 (mean percentage accuracy - mean speed per question). Speed per question was quantified as the number of responses per minute. The impulsivity fac- 
Table 2. Differences between abstinent MDMA users and controls on WRAIR PAB accuracy and behavioral impulsivity during $40 \mathrm{~h}$ of sleep deprivation

\begin{tabular}{|c|c|c|c|c|}
\hline Task & Measure & Group & Day & Group X Day \\
\hline \multirow[t]{2}{*}{ Code Substitution } & Accuracy & $F=6.58, p=0.01$ & $F=9.01, p \leq \mathbf{0 . 0 0 0 1}$ & $F=2.43, p=\mathbf{0 . 0 7}$ \\
\hline & Impulsivity & $F=5.34, p=\mathbf{0 . 0 3}$ & $F=6.38, p=\mathbf{0 . 0 0 0 5}$ & $F=3.61, p=0.02$ \\
\hline \multirow[t]{2}{*}{ Delayed Recall } & Accuracy & $F=0.00, p=0.97$ & $F=7.62, p=\mathbf{0 . 0 0 0 1}$ & $F=2.49, p=\mathbf{0 . 0 6}$ \\
\hline & Impulsivity & $F=5.34, p=\mathbf{0 . 0 3}$ & $F=4.29, p=\mathbf{0 . 0 0 7}$ & $F=3.23, p=\mathbf{0 . 0 3}$ \\
\hline \multirow[t]{2}{*}{ Logical Reasoning } & Accuracy & $F=1.19, p=0.28$ & $F=3.84, p=0.01$ & $F=1.32, p=0.27$ \\
\hline & Impulsivity & $F=0.23, p=0.63$ & $F=2.52, p=0.06$ & $F=0.61, p=0.61$ \\
\hline \multirow[t]{2}{*}{ Manikin Figure } & Accuracy & $F=1.43, p=0.24$ & $F=1.70, p=0.17$ & $F=0.09, p=0.96$ \\
\hline & Impulsivity & $F=5.37, p=\mathbf{0 . 0 3}$ & $F=0.28, p=0.84$ & $F=0.33, p=0.80$ \\
\hline \multirow[t]{2}{*}{ Matching to Sample } & Accuracy & $F=2.64, p=0.11$ & $F=0.22, p=0.88$ & $F=0.58, p=0.63$ \\
\hline & Impulsivity & $F=2.51, p=0.12$ & $F=1.41, p=0.24$ & $F=0.76, p=0.52$ \\
\hline \multirow[t]{2}{*}{ Serial Add and Subtract } & Accuracy & $F=0.98, p=0.33$ & $F=2.82, p=0.04$ & $F=1.03, p=0.38$ \\
\hline & Impulsivity & $F=4.33, p=0.04$ & $F=1.85, p=0.14$ & $F=0.73, p=0.53$ \\
\hline
\end{tabular}

Results from the SAS Proc Mixed function with an autoregressive covariance. Variables included in the model are Drug, Group, Gender, Day, Time, and Group $\times$ Day interaction. Bold indicates significant or near-significant differences between groups.

tor results in high scores when individuals perform quickly and inaccurately, and low scores when they perform slowly and accurately. When a main effect of Group or a Group $\times$ Day interaction was found, the leastsquares means of fixed effects were compared at individual time points to determine the nature of these findings. The seven components of the PSQI were compared in the two groups using ordinal regression. Logistic regression was used to compare groups on the latent global dichotomous variable (with a score of $>5$ being the cutoff as an indicator for sleep disturbance). Mediation was calculated using methods described by Kenny (2009), using multiple linear regressions with a sandwich variance estimator and a Monte Carlo method (MacKinnon et al., 2004; Selig and Preacher, 2009), adjusting for gender. The global PSQI score was used in the mediation analysis.

In an effort to explore the potential role of previous cocaine, tobacco, and alcohol use on $\mathrm{PAB}$ performance during sleep deprivation, Proc Mixed regressions, with repeated measures adjusting for gender, were used to measure the strength of association between frequency of drug use during the previous 6 months and accuracy and impulsivity measures that differed significantly between groups. Frequency of hallucinogen use during the previous 6 months was insufficiently high to attain strength of association.

\section{Results}

Demographics and MDMA use characteristics of the two subject groups are shown in Table 1. The two groups were well matched with regard to age, education and intelligence [as reflected by the North American Adult Reading Test (NAART)], and gender distribution. A similar number of MDMA users and controls reported having used marijuana, alcohol, and tobacco in the past, but a greater proportion of MDMA users had previously used hallucinogens and cocaine (Table 1). A small number of MDMA users, but no controls, reported previous exposure to opioids and benzodiazepines (Table 1).

\section{Effect of sleep deprivation}

Sleep deprivation led to impaired performance on five of the seven tasks in the WRAIR PAB, as reflected by significant main effects of Day (Table 2) on either accuracy or impulsivity, with only time estimation and a matching-to-sample task remaining unaffected by sleep loss.

\section{Accuracy}

MDMA users were less accurate than controls on the Code Substitution task (Table 2, Fig. 1), as reflected by a main effect of group in accuracy on these two tasks. In addition, MDMA users tended to be more susceptible to the effects of sleep deprivation on accuracy of performance for the Code Substitution and De-
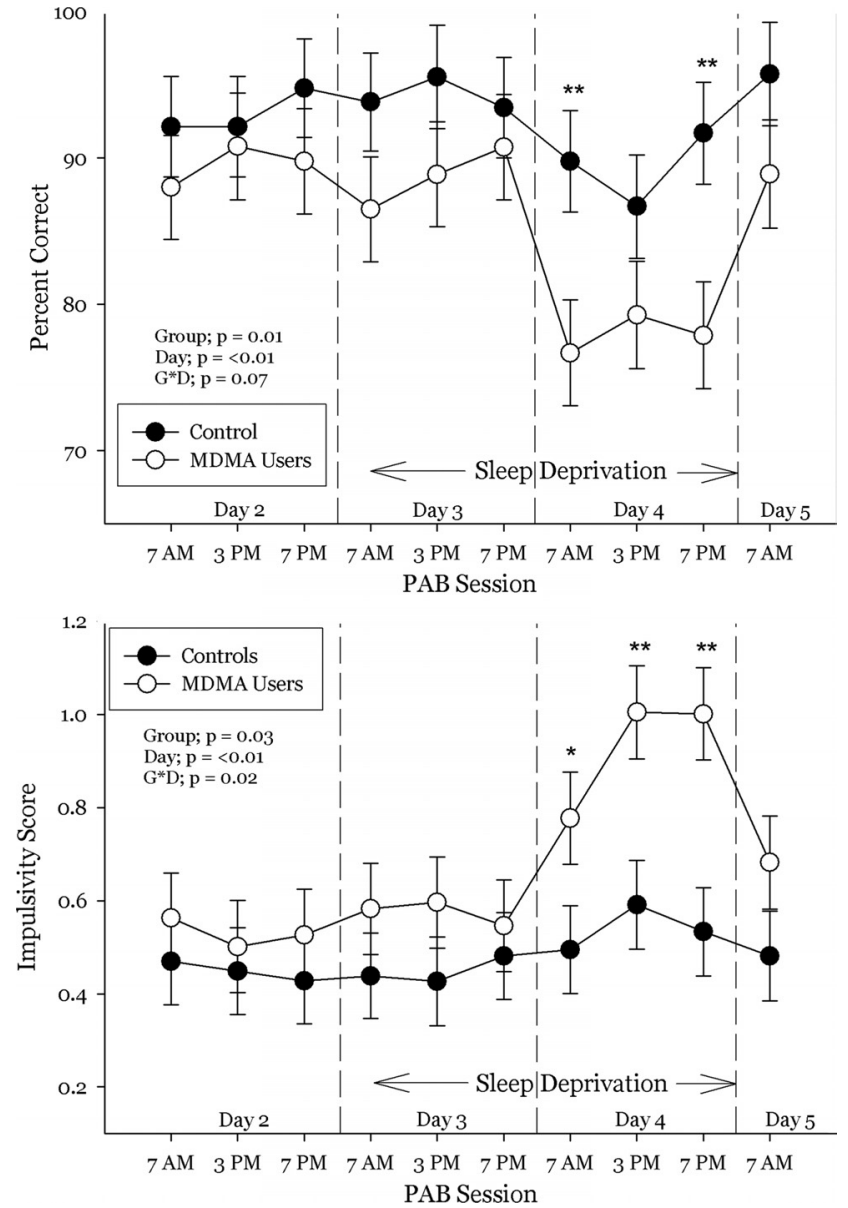

Figure 1. Accuracy and impulsivity on the Code Substitution task of the WRAIR PAB before, during, and after $40 \mathrm{~h}$ of total sleep deprivation. Results were compared using the SAS Proc Mixed function, with gender as the covariate, MDMA status as the between-group variable, and Time and Day as within-subject variables. ${ }^{*} p<0.05 ;{ }^{* *} p<0.01$. G*D, Group $\times$ Day interaction. Error bars represent SEMs.

layed Recall tasks, as reflected by near-significant Group $\times$ Day interactions for these tasks (Table 2; Figs. 1, 2).

\section{Impulsivity}

MDMA users exhibited higher levels of impulsive performance (i.e., performed more quickly at the expense of accuracy) on the Code Substitution and Delayed Recall tasks, as well as the Mani- 

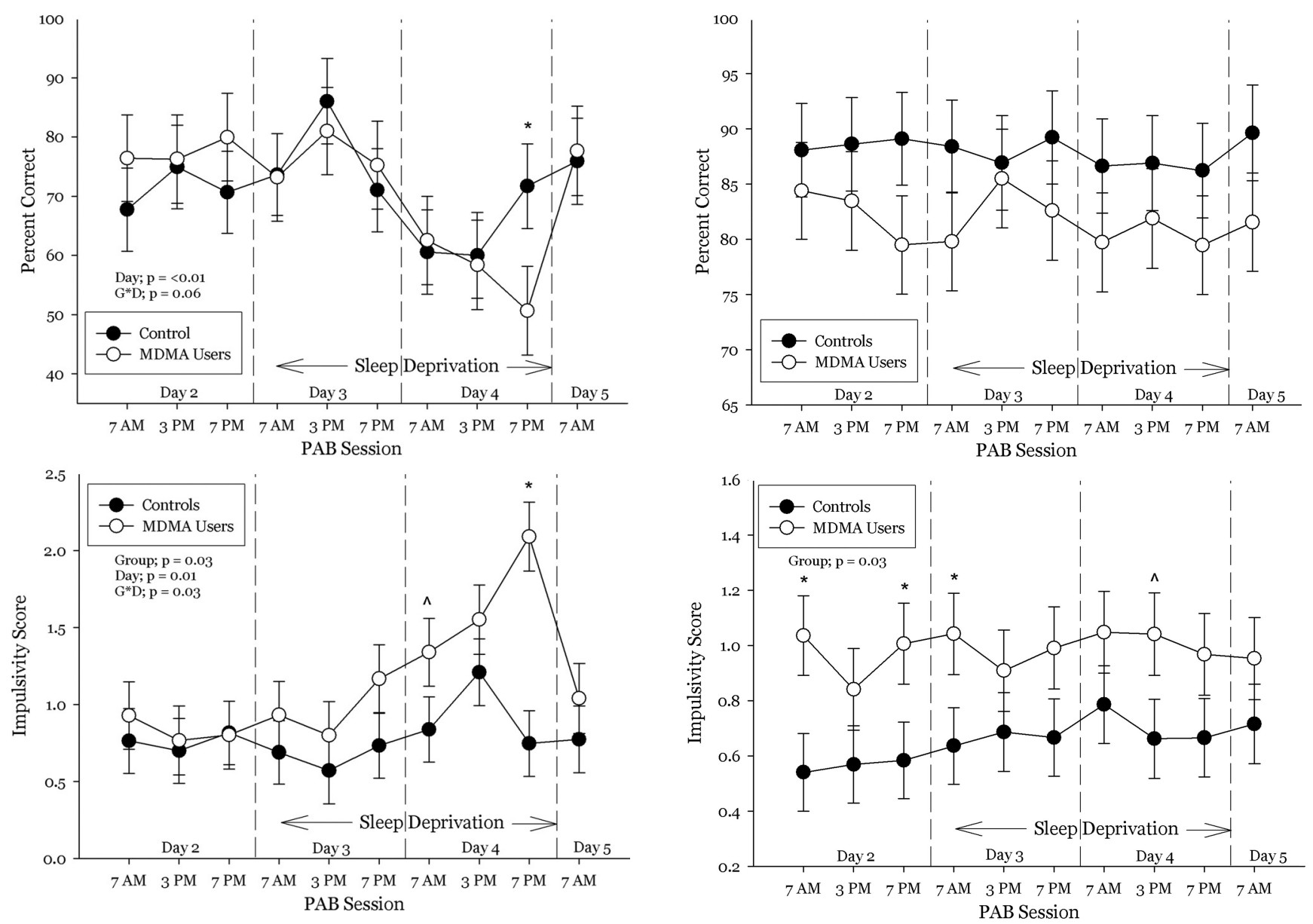

Figure 2. Accuracy and impulsivity on the Delayed Recall task of the WRAIR PAB before, during, and after $40 \mathrm{~h}$ of total sleep deprivation. Results were compared using the SAS Proc Mixed function, with gender as the covariate, MDMA status as the between-group variable, and Time and Day as within-subject variables. ${ }^{\wedge} p<0.10$; ${ }^{*} p<0.05$. G*D, Group $\times$ Day interaction. Error bars represent SEMs.

kin and Serial Add and Subtract tasks (Table 2, Figs. 1-4), as reflected by a main effect of group in impulsivity on each of these tasks. MDMA users were also more susceptible to the effects of sleep deprivation on behavioral impulsivity while performing the Code Substitution and Delayed Recall tasks (Figs. 1, 2), as reflected by a Day $\times$ Group interaction on these two measures. As expected, impulsivity and accuracy for these two measures were inversely related, indicating that subjects increased their speed of performance at the expense of accuracy.

\section{Recovery sleep}

For all tasks, recovery sleep led to a reversal of the effects of sleep deprivation in both groups (Figs. 1-4), with performance and accuracy scores both returning to baseline levels except for behavioral impulsivity in MDMA users on the Serial Add and Subtract task, which remained higher than baseline at the final data collection point.

\section{PSQI}

Three of 19 MDMA users and 2 of 21 controls had missing data for the PSQI. Seven of the remaining 16 MDMA users reported a global score $>5(6.4 \pm 4.2$; mean $\pm \mathrm{SD})$, whereas only 1 of the remaining 19 controls reported a score $>5(2.9 \pm 1.8)$. MDMA users were 15 times as likely to self-report a global score cutoff of $>5(p=0.02)($ Table 3$)$.

Figure 3. Accuracy and impulsivity on the Manikin Figure task of the WRAIR PAB before, during, and after $40 \mathrm{~h}$ of total sleep deprivation. Results were compared using the SAS Proc Mixed function, with gender as the covariate, MDMA status as the between-group variable, and Time and Day as within-subject variables. ${ }^{\wedge} p<0.10 ;{ }^{*} p<0.05$. Error bars represent SEMs.

\section{Mediation}

The effect of MDMA use on the PAB performances of day 4 during sleep deprivation was tested for mediation from previously self-reported sleep disturbances, via the PSQI. The Monte Carlo method for assessing mediation indicated that preexisting sleep disturbance mediated increased impulsivity of performance on the delayed recall and Logical Reasoning task after sleep deprivation, as well as decreased accuracy on the logical reasoning and Serial Add and Subtract tasks (Table 4).

\section{Relationship to "other drug use"}

There were no significant relationships between frequency of hallucinogen or cocaine use on accuracy or impulsivity during sleep deprivation on tasks that differed between groups. Frequency of alcohol use was predictive of impulsive responding on the Code Substitution task $(p=0.002)$ and the Manikin task $(p=0.02)$ during sleep deprivation. Increased tobacco use was associated with increased accuracy on the Serial Add and Subtract task during sleep deprivation $(p=0.01)$.

\section{Discussion}

The results of the present study indicate that abstinent MDMA users are more susceptible to the negative cognitive consequences of $40 \mathrm{~h}$ of total sleep deprivation than healthy age- and gendermatched controls on tasks of working and short-term memory. Notably, for both tasks, deterioration in performance appears to 

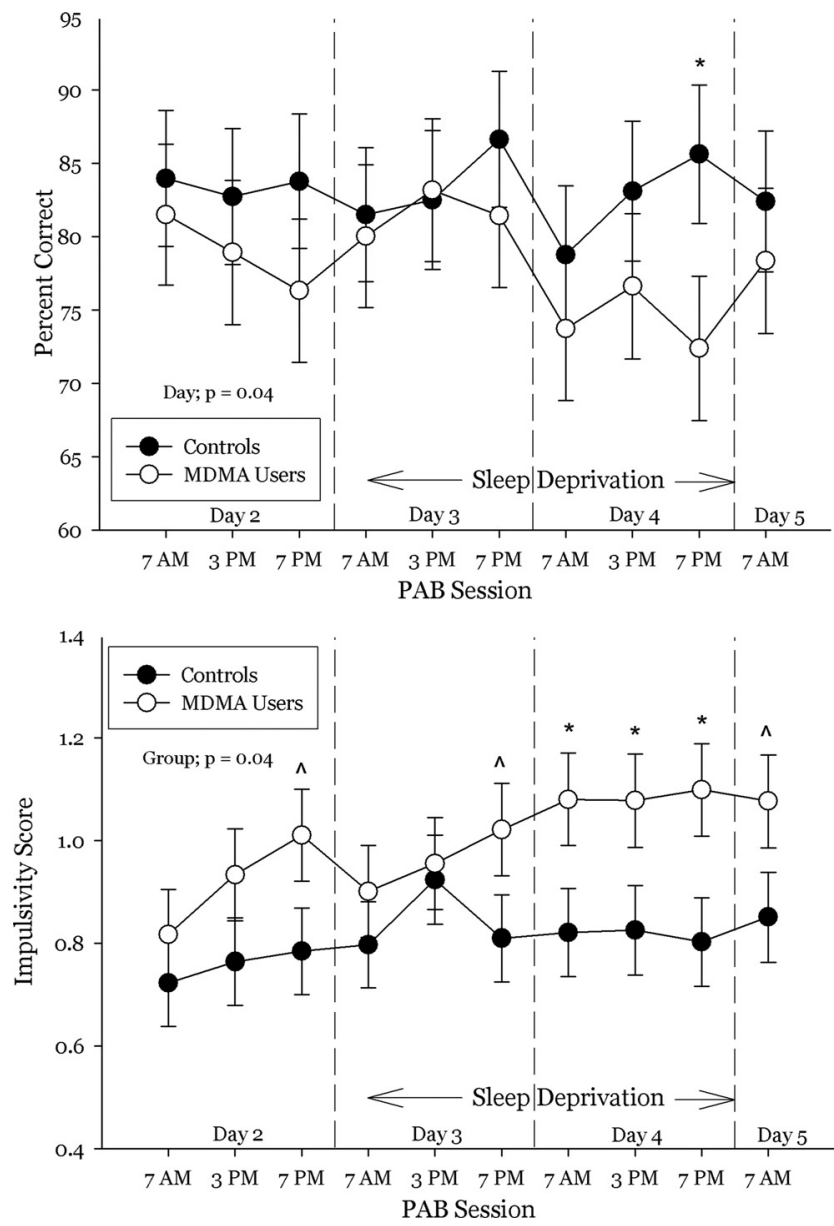

Figure 4. Accuracy and impulsivity on the Serial Add and Subtract task of the WRAIR PAB before, during, and after $40 \mathrm{~h}$ of total sleep deprivation. Results were compared using the SAS Proc Mixed function, with gender as the covariate, MDMA status as the between-group variable, and Time and Day as within-subject variables. ${ }^{\wedge} p<0.10 ;{ }^{*} p<0.05$.

Table 3. Differences between abstinent MDMA users and controls on PSQI measures

\begin{tabular}{|c|c|c|c|c|c|}
\hline \multirow[b]{2}{*}{ Sleep category } & \multirow{2}{*}{$\begin{array}{l}\text { Odds } \\
\text { ratio }\end{array}$} & \multicolumn{2}{|c|}{$\begin{array}{l}95 \% \text { Confidence } \\
\text { limits }\end{array}$} & \multirow{2}{*}{$\begin{array}{l}\text { Gender } \\
(p)\end{array}$} & \multirow{2}{*}{$\begin{array}{l}\text { MDMA } \\
(p)\end{array}$} \\
\hline & & Lower & Upper & & \\
\hline Quality & 9.8 & 1.8 & 53.9 & 0.24 & 0.01 \\
\hline Latency & 1.7 & 0.5 & 5.9 & 0.27 & 0.41 \\
\hline Duration & 4.4 & 1.1 & 17.2 & 0.34 & 0.03 \\
\hline Efficiency & 10.2 & 1.7 & 62.6 & 0.53 & 0.01 \\
\hline Disturbances & 12.1 & 1.3 & 112.8 & 0.19 & 0.03 \\
\hline Medication & N/A & N/A & $\mathrm{N} / \mathrm{A}$ & N/A & N/A \\
\hline Daytime dysfunction & 5.5 & 0.8 & 37.6 & 0.02 & 0.08 \\
\hline Latent global & 14.9 & 1.5 & 146.0 & 0.75 & 0.02 \\
\hline
\end{tabular}

N/A, Not applicable.

be primarily related to an increase in impulsive responding. In particular, as the period of sleep deprivation progressed, MDMA users responded more quickly, at the expense of accuracy. Tests of mediation indicated that deterioration in performance on three of seven cognitive tasks during sleep deprivation was mediated by previous sleep quality, as measured by the PSQI. This observation is consistent with the hypothesis that cognitive deficits in MDMA users are related, in part, to sleep disturbance.

The present findings confirm and extend previous results demonstrating poorer cognitive performance in MDMA users
Table 4. Mediation effects of baseline sleep disturbances on cognitive decline during sleep deprivation in MDMA users

\begin{tabular}{|c|c|c|c|c|c|}
\hline \multirow[b]{2}{*}{ Estimated variance } & \multirow[b]{2}{*}{ a } & \multirow[b]{2}{*}{ b } & \multicolumn{2}{|c|}{ Monte Carlo (95\% Cl) } & \multirow[b]{2}{*}{ Monte Carlo $(p)$} \\
\hline & & & Lower & Upper & \\
\hline \multicolumn{6}{|l|}{ Code Substitution } \\
\hline Accuracy & 3.70 & -12.03 & -124.04 & 17.00 & $p>0.05$ \\
\hline Impulsivity & 3.70 & 0.48 & -0.20 & 4.41 & $p>0.05$ \\
\hline \multicolumn{6}{|l|}{ Delayed Recall } \\
\hline Accuracy & 3.70 & -5.86 & -136.18 & 85.08 & $p>0.05$ \\
\hline Impulsivity & 3.70 & 0.84 & 0.01 & 7.29 & $p<0.05$ \\
\hline \multicolumn{6}{|l|}{ Logical Reasoning } \\
\hline Accuracy & 3.70 & -16.10 & -139.40 & -0.13 & $p<0.05$ \\
\hline Impulsivity & 3.70 & 1.12 & 0.47 & 9.22 & $p<0.05$ \\
\hline \multicolumn{6}{|l|}{ Manikin Figure } \\
\hline Accuracy & 3.70 & -15.62 & -140.63 & 4.28 & $p>0.05$ \\
\hline Impulsivity & 3.70 & 0.36 & -0.93 & 4.05 & $p>0.05$ \\
\hline \multicolumn{6}{|l|}{ Matching to Sample } \\
\hline Accuracy & & 3.70 & -7.92 & -107.21 & 36.15 \\
\hline Impulsivity & & 3.70 & 0.47 & -0.26 & 4.37 \\
\hline \multicolumn{6}{|c|}{ Serial Add and Subtract } \\
\hline Accuracy & 3.70 & -22.54 & -177.21 & -13.56 & $p<0.05$ \\
\hline Impulsivity & 3.70 & 0.20 & -0.83 & 2.55 & $p>0.05$ \\
\hline
\end{tabular}

(see Introduction) and provide additional evidence that impulsive responding may underlie poorer performance on some cognitive tests (Morgan et al., 2006; McCann et al., 2007). In the present study, sleep deprivation in MDMA users, but not controls, was associated with increased behavioral impulsivity. This response to sleep deprivation is atypical because the usual response to sleep deprivation in a healthy adult population is to maintain accuracy at the expense of speed (i.e., the "speed accuracy trade off") (Webb and Levy, 1982; Angus and Heslegrave, 1985).

It is notable that the two tasks that were differentially affected by sleep deprivation were tasks of working and short-term memory, the cognitive domains most consistently found to be impaired in MDMA users (Parrott, 2000; Kalechstein et al., 2007; de Win et al., 2008; Zakzanis et al., 2007) and that are known to be negatively impacted by sleep deprivation (Alhola and PoloKantola, 2007). Sustained attention is the cognitive domain known to be most immediately and severely impacted by sleep deprivation (Banks and Dinges, 2007; Lim and Dinges, 2008), but in the present study, a similar decline in both groups was observed on the Serial Add and Subtract task, a task of sustained attention. An extensive body of data indicates that with prolonged wakefulness, individuals develop an increasing number of behavioral lapses that are thought to be related to "microsleeps" (Kleitman, 1963; Dinges and Kribbs, 1991) and that sustained attention tasks are acutely sensitive to this effect because subjects miss cues that are presented while they are asleep. Working memory has also been found to be negatively influenced by sleep deprivation (Alhola and Polo-Kantola, 2007), possibly as a function of an inability to sustain attention on the memory task (i.e., sleeping when the stimulus to be remembered is presented), rather than problems with working memory function per se. The observation that MDMA users are more sensitive to the effects of sleep deprivation on tasks of working and short-term memory is consistent with the notion that cognitive deficits in MDMA users could be related, in part, to chronic sleep disturbance (McCann et al., 2007).

A large body of preclinical data, as well as a growing number of clinical studies, implicates brain 5-HT systems in cognitive function, including memory processes (Schmitt et al., 2006; King et al., 2008). Furthermore, in MDMA users, working memory def- 
icits have been found to be inversely related to brain SERT binding density (McCann et al., 2008). Brain 5-HT systems are also implicated in impulsivity (Hollander and Rosen, 2000; Oquendo and Mann, 2000), with decreases in brain 5-HT markers being associated with increased impulsivity. Although MDMA subjects in the current study did not undergo PET imaging as part of this research, their use characteristics are similar to those of subjects previously found to have significant global reductions of the SERT (McCann et al., 1998, 2005, 2008). Therefore, it is plausible, given the known role of 5-HT in cognitive function and impulsivity, that MDMA-induced 5-HT neurotoxicity is involved in the current observations.

Although the present findings suggest that sleep disturbance may play a role in the cognitive deficits seen in MDMA users, they do not clarify the neurobiological basis for these deficits. In particular, it is possible that MDMA-induced 5-HT neurotoxicity results in a disturbance in normal sleep mechanisms and that sleep disturbance leads to cognitive dysfunction. It is also possible that MDMA-induced 5-HT neurotoxicity leads to direct damage of brain systems involved in cognitive function, or could impact both sleep and cognitive processes. Conceivably, cognitive deficits, impulsive responding, and sleep alterations could all be unrelated to brain 5-HT neurotoxicity. Future studies using functional imaging methods, possibly in combination with PET measures of 5-HT neuronal integrity, could be useful in clarifying this issue. In addition, a future study comparing cognitive performance in MDMA users and an age- and gender-matched group of patients with chronic sleep disturbance but no previous MDMA use would be helpful in determining the role of sleep disruption per se in the present findings.

Cognitive deficits in MDMA users are subtle and, indeed, only detected using sensitive quantitative testing measures. This fact, plus the fact that cognitive testing scores in MDMA users often overlap with those seen in healthy volunteers, is sometimes used to argue that the deleterious effects of MDMA on cognition are not clinically meaningful. The present findings suggest an alternate interpretation of the data. In particular, as is common after various forms of neural injury, it is likely that compensatory neuroadaptive processes occur after MDMA-induced 5-HT neurotoxicity. This view is supported by functional neuroimaging studies demonstrating abnormal activation patterns during memory processing (Moeller et al., 2004; Daumann et al., 2005; Raj et al., 2009). However, when stressed, either by sleep deprivation or by pharmacological challenge (McCann et al., 2005), these compensatory mechanisms begin to fail. It remains to be seen whether, with advanced age and normal loss of brain dopamine and 5-HT neurons, as well as diminished sleep quality, cognitive deficits in MDMA users develop into clinically significant cognitive impairment.

Limitations of the present study include the fact that MDMA subjects were more likely to report lifetime exposure to other drugs than controls. These other drugs could, in theory, play a role in the cognitive deficits and differential effect of sleep deprivation found in the current study. However, previous studies that excluded MDMA users who had been exposed to amphetamines (McCann et al., 1998, 1999, 2007) controlled for other drugs of abuse (Schilt et al., 2008), or only included MDMA users who had relatively low other drug exposure (Schilt et al., 2007), have all found MDMA users to exhibit deficits in memory function. Furthermore, subjects in the current study had abstained from all drugs for at least 2 weeks, and most substances for months, at the time of testing. In the current study, there was no relationship between frequency of cocaine use and cognitive performance during sleep deprivation. Frequency of alcohol use was associated with increased impulsivity on two tasks. However, both groups used alcohol, and no subject met criteria for alcohol abuse. Frequency of tobacco use, which was greater in MDMA users, was associated with improved accuracy on an attention task during sleep deprivation. Therefore, although other drug use could have theoretically played a role in the current findings, the evidence for such an effect is lacking. Another limitation of this study is that drug use reports were retrospective, and could be inaccurate or clouded by time or intoxication. As with all retrospective studies, it is possible that differences found in MDMA users and controls predated or even contributed to the onset of MDMA use. However, we have previously found reductions of brain SERTs, as measured by PET, to be significantly associated with selfreported lifetime MDMA exposure (McCann et al., 2005) and cognitive deficits to be related to SERT binding (McCann et al., 2008).

In conclusion, the finding that MDMA users are differentially sensitive to the effects of sleep deprivation on tasks of sustained attention and working memory is consistent with the hypothesis that cognitive deficits in MDMA users are related, in part, to sleep disturbance. Furthermore, tests of mediation indicate that selfreported poor sleep quality during the month before enrollment played a role in increased impulsivity and/or decreased accuracy during sleep deprivation in MDMA users. Additional research will be required to determine the precise mechanisms underlying the effects of sleep deprivation on cognitive function in MDMA users and to determine whether sleep disturbance and cognitive dysfunction in MDMA users is related to MDMA-induced 5-HT neurotoxicity.

\section{References}

Alhola P, Polo-Kantola P (2007) Sleep deprivation: impact on cognitive performance. Neuropsychiatr Dis Treat 3:553-567.

Angus RG, Heslegrave RJ (1985) Effects of sleep and sustained cognitive performance during a command and control situation. Behav Res Methods 17:55-67.

Banks S, Dinges DF (2007) Behavioral and physiological consequences of sleep restriction. J Clin Sleep Med 3:519-528.

Bolla KI, McCann UD, Ricaurte GA (1998) Memory impairment in abstinent MDMA ("ecstasy”) users. Neurology 51:1532-1537.

Buchert R, Thomasius R, Nebeling B, Petersen K, Obrocki J, Jenicke L, Wilke F, Wartberg L, Zapletalova P, Clausen M (2003) Long-term effects of "ecstasy" use on serotonin transporters of the brain investigated by PET. J Nucl Med 44:375-384.

Buchert R, Thomasius R, Wilke F, Petersen K, Nebeling B, Obrocki J, Schulze O, Schmidt U, Clausen M (2004) A voxel-based PET investigation of the long-term effects of "ecstasy" consumption on brain serotonin transporters. Am J Psychiatry 161:1181-1189.

Buysse DJ, Reynolds CF, Monk TH, Berman SR, Kupfer DJ (1989) The Pittsburgh Sleep Quality Index (PSQI): a new instrument for psychiatric research and practice. Psychiatry Res 28:193-213.

Carskadon MA, Acebo C, Jenni OG (2004) Regulation of adolescent sleep: implications for behavior. Ann N Y Acad Sci 1021:276-291.

Colado MI, O'Shea E, Granados R, Murray TK, Green AR (1997) In vivo evidence for free radical involvement in the degeneration of rat brain 5-HT following administration of MDMA ("Ecstasy") and p-chloroamphetamine but not the degeneration following fenfluramine. Br J Pharmacol 121:889-900.

Daumann J, Fischermann T, Heekeren K, Henke K, Thron A, GouzoulisMayfrank E (2005) Memory-related hippocampal dysfunction in poly-drug ecstasy (3,4-methylenedioxymethamphetamine) users. Psychopharmacology (Berl) 180:607-611.

de Win MML, Jager G, Booij J, Reneman L, Schilt T, Lavini C, Olabarriaga SD, den Heeten GJ, van den Brink W (2008) Sustained effects of ecstasy on the human brain: a prospective neuroimaging study in novel users. Brain 131:2936-2945.

Dinges DF, Kribbs NB (1991) Performing while sleepy: effects of experi- 
mentally induced sleepiness. In: Sleep, sleepiness and performance (Monk TH, ed), pp 97-128. Chichester, UK: Wiley.

First MB, Spitzer RL, Gibbon M, Williams JB (1997) Structured clinical interview for DSM-IV Axis I disorders (SCID-I), clinician version. Arlington, VA: American Psychiatric Publishers Inc.

Green AR, Mechan AO, Elliott JM, O'Shea E, Colado MI (2003) The pharmacology and clinical pharmacology of 3,4-methylenedioxymethamphetamine (MDMA, "ecstasy"). Pharmacol Rev 55:463-508.

Hatzidimitriou G, McCann UD, Ricaurte GA (1999) Altered serotonin innervation patterns in the forebrain of monkeys treated with $( \pm) 3,4-$ methylenedioxymethamphetamine seven years previously: factors influencing abnormal recovery. J Neurosci 19:5096-5107.

Hollander E, Rosen J (2000) Impulsivity. J Psychopharmacol 14:S39-S44.

Johnston LD, O'Malley PM, Bachman, JG, Schulenberg, JE (2009) Monitoring the future national results on adolescent drug use: overview of key findings, 2008 (NIH Publication No. 09-7401). Bethesda, MD: NIDA.

Kalechstein AD, De La Garza R 2nd, Mahoney JJ 3rd, Fantegrossi WE, Newton TF (2007) MDMA use and neurocognition: a meta-analytic review. Psychopharmacology (Berl) 189:531-537.

Kenny DA (2009) Mediation. Retrieved September 30, 2009. Available from http://davidakenny.net/cm/mediate.htm.

King MV, Marsden CA, Fone KC (2008) A role for the 5-HT(1A), 5-HT(4) and 5-HT(6) receptors in learning and memory. Trends Pharmacol Sci 29:482-492.

Kish S, Fitzmaurice P, Chang L, Furukawa Y, Tong J (2008) Low striatal serotonin transporter protein in a human polydrug MDMA (ecstasy) user: a case study. J Psychopharmacol. Advance online publication. Retrieved October 15, 2009. doi: 10.1177/0269881108097724.

Kleitman N (1963) Sleep and wakefulness, Ed 2. Chicago: University of Chicago.

Lim J, Dinges DF (2008) Sleep deprivation and vigilant attention. Ann N Y Acad Sci 1129:305-322.

MacKinnon DP, Lockwood CM, Williams J (2004) Confidence limits for the indirect effect: distribution of the product and resampling methods. Multivar Behav Res 39:99-128.

McCann UD, Ricaurte GA (2007) Effects of (+/-)3,4-methylenedioxymethamphetamine (MDMA) on sleep and circadian rhythms. Sci World J 7:231-238.

McCann UD, Szabo Z, Scheffel U, Dannals RF, Ricaurte GA (1998) Positron emission tomographic evidence of toxic effect of MDMA ("ecstasy") on brain serotonin neurons in human beings. Lancet 352:1433-1437.

McCann UD, Mertl M, Eligulashvili V, Ricaurte GA (1999) Cognitive performance in $(+/-) 3,4$-methylenedioxymethamphetamine (MDMA, "ecstasy") users: a controlled study. Psychopharmacology (Berl) 143:417425.

McCann UD, Szabo Z, Seckin E, Rosenblatt P, Mathews WB, Ravert HT, Dannals RF, Ricaurte GA (2005) Quantitative PET studies of the serotonin transporter in MDMA users and controls using [11C]McN5652 and [11C]DASB. Neuropsychopharmacology 30:1741-1750.

McCann UD, Peterson SC, Ricaurte GA (2007) The effect of catecholamine depletion by alpha-methyl-para-tyrosine on measures of cognitive performance and sleep in abstinent MDMA users. Neuropsychopharmacology 32:1695-1706.

McCann UD, Szabo Z, Vranesic M, Palermo M, Mathews WB, Ravert HT, Dannals RF, Ricaurte GA (2008) Positron emission tomographic studies of brain dopamine and serotonin transporters in abstinent $(+/-) 3,4$ methylenedioxymethamphetamine ("ecstasy") users: relationship to cognitive performance. Psychopharmacology (Berl) 200:439-450.

Mechan A, Yuan J, Hatzidimitriou G, Irvine RJ, McCann UD, Ricaurte GA (2006) Pharmacokinetic profile of single and repeated oral doses of MDMA in squirrel monkeys: relationship to lasting effects on brain serotonin neurons. Neuropsychopharmacology 31:339-350.

Moeller FG, Steinberg JL, Dougherty DM, Narayana PA, Kramer LA, Renshaw PF (2004) Functional MRI study of working memory in MDMA users. Psychopharmacology (Berl) 177:185-194.

Morgan MJ, Impallomeni LC, Pirona A, Rogers RD (2006) Elevated impulsivity and impaired decision-making in abstinent ecstasy (MDMA) users compared to polydrug and drug-naive controls. Neuropsychopharmacology 31:1562-1573.

Newhouse PA, Belenky G, Thomas M, Thorne D, Sing HC, Fertig J (1989) The effects of $d$-amphetamine on arousal, cognition and mood after prolonged total sleep deprivation. Neuropsychopharmacology 2:153-164.
O'Brien EM, Mindell JA (2005) Sleep and risk-taking behavior in adolescents. Behav Sleep Med 3:113-133.

O’Hearn E, Battaglia G, De Souza EB, Kuhar MJ, Molliver ME (1988) Methylenedioxyamphetamine (MDA) and methylenedioxymethamphetamine (MDMA) cause selective ablation of serotonergic axon terminals in forebrain: immunocytochemical evidence for neurotoxicity. J Neurosci 8:2788-2803.

Oquendo MA, Mann JJ (2000) The biology of impulsivity and suicidality. Psychiatr Clin North Am 23:11-25.

Parrott AC (2000) Human research on MDMA (3,4-methylene-dioxymethamphetamine) neurotoxicity: cognitive and behavioural indices of change. Neuropsychobiology 42:17-24.

Quednow BB, Kuhn KU, Hoppe C, Westheide J, Maier W, Daum I, Wagner M (2007) Elevated impulsivity and impaired decision-making cognition in heavy users of MDMA ("ecstasy"). Psychopharmacology (Berl) 189:517-530.

Raj V, Liang H, Woodward N, Bauernfeind A, Lee J, Dietrich M, Park S, Cowan R (2009) MDMA (ecstasy) use is associated with reduced BOLD signal change during semantic recognition in abstinent human polydrug users: a preliminary fMRI study. J Psychopharmacol (Berl). Advance online publication. Retrieved October 15, 2009. doi:10.1177/0269881109103203.

Reneman L, Lavalaye J, Schmand B, de Wolff FA, van den Brink W, den Heeten GJ, Booij J (2001) Cortical serotonin transporter density and verbal memory in individuals who stopped using 3,4-methylenedioxymethamphetamine (MDMA or "ecstasy"): preliminary findings. Arch Gen Psychiatry 58:901-906.

Ricaurte GA, DeLanney LE, Wiener SG, Irwin I, Langston JW (1988) 5 -Hydroxyindoleacetic acid in cerebrospinal fluid reflects serotonergic damage induced by 3,4 methylenedioxymethamphetamine in CNS of non-human primates. Brain Res 474:359-363.

Ricaurte GA, Martello AL, Katz JL, Martello MB (1992) Lasting effects of (+/-)3,4-methylenedioxymethamphetamine (MDMA) on central serotonergic neurons in nonhuman primates: neurochemical observations. J Pharmacol Exp Ther 261:616-622.

Salkind NJ, Wright JC (1977) The development of reflection-impulsivity and cognitive efficiency: an integrated model. Hum Dev 20:377-387.

Scheffel U, Szabo Z, Mathews WB, Finley PA, Dannals RF, Ravert HT, Szabo K, Yuan J, Ricaurte GA (1998) In vivo detection of short- and long-term MDMA neurotoxicity-a positron emission tomography study in the living baboon brain. Synapse 29:183-192.

Schilt T, de Win MM, Koeter M, Jager G, Korf DJ, van den Brink W, Schmand B (2007) Cognition in novice ecstasy users with minimal exposure to other drugs: a prospective cohort study. Arch Gen Psychiatry 64:728-736.

Schilt T, de Win MM, Jager G, Koeter MW, Ramsey NF, Schmand B, van den Brink W (2008) Specific effects of ecstasy and other illicit drugs on cognition in poly-substance users. Psychol Med 38:1309-1317.

Schmidt CJ (1987) Neurotoxicity of the psychedelic amphetamine, methylenedioxymethamphetamine. J Pharmacol Exp Ther 240:1-7.

Schmitt JA, Wingen M, Ramaekers JG, Evers EA, Riedel WJ (2006) Serotonin and human cognitive performance. Curr Pharm Des 12:2473-2486.

Selig JP, Preacher KJ, eds (2009) Monte Carlo method for assessing mediation. The University of Kansas. Retrieved September 29, 2009. Available at http://www.people.ku.edu/ preacher/medmc/medmc.htm.

Semple DM, Ebmeier KP, Glabus MF, O'Carroll RE, Johnstone EC (1999) Reduced in vivo binding to the serotonin transporter in the cerebral cortex of MDMA ("ecstasy") users. Br J Psychiatry 175:63-69.

Thomasius R, Zapletalova P, Petersen K, Buchert R, Andresen B, Wartberg L, Nebeling B, Schmoldt A (2006) Mood, cognition and serotonin transporter availability in current and former ecstasy (MDMA) users: the longitudinal perspective. J Psychopharmacol 20:211-225.

Thorne DR, Genser SG, Sing HC, Hegge FK (1985) The Walter Reed Performance Assessment Battery. Neurobehav Toxicol Teratol 7:415-418.

Webb W, Levy C (1982) Age, sleep deprivation and performance. Psychophysiology 19:272-276.

Wechsler D (1981) Wechsler adult intelligence scale-revised: manual. New York: Psychological Corporation.

Zakzanis KK, Campbell Z, Jovanovski D (2007) The neuropsychology of ecstasy (MDMA) use: a quantitative review. Hum Psychopharmacol 22: 427-435. 